\title{
Spark plasma sintering of CNT-NiAl nanocomposites - Process parameter, densification mechanism, and grain analysis
}

\author{
Olusoji Oluremi Ayodele* (D), Mary Ajimegoh Awotunde, Bukola Joseph Babalola, and Peter Apata Olubambi \\ Centre for Nanoengineering and Tribocorrosion, School of Mining, Metallurgy and Chemical Engineering, University \\ of Johannesburg, Johannesburg, South Africa
}

Received: 13 June 2021 / Accepted: 31 July 2021

\begin{abstract}
The densification process and grain analysis of consolidated NiAl-CNT composites at $1000^{\circ} \mathrm{C}$, and at varied heating rates from $50^{\circ} \mathrm{C} / \mathrm{min}$ to $150^{\circ} \mathrm{C} / \mathrm{min}$ was investigated. The results revealed the effect of heating rate on the densification behaviour of the samples. The displacement of the composites decreased from $3.39 \mathrm{~mm}$ to $2.63 \mathrm{~mm}$ with increasing heating rate, while the porosity increased by $69 \%$ at rapid heating rate. The grain analysis of the sintered samples through the electron backscattered (EBSD) technique indicates the evolution of bigger grains as the heating rate proceeds higher. Furthermore, the mean grain size of the consolidated composites increased from $3.93 \mu \mathrm{m}$, to $8.05 \mu \mathrm{m}$ due to the concentration of defects. Interestingly, there was no texture or predominance of any color evolution in the sintered materials.
\end{abstract}

Keywords: Grain size / electron backscattered diffraction / porosity / densification and heating rate

\section{Introduction}

Spark plasma sintering (SPS) is a promising sintering technique which has captivated the attention of a lot of researchers in the field of science and engineering because of the advantages it provided over the traditional sintering processes (TS) [1]. The TS methods are characterized with long sintering temperatures and provides limited control over the properties and microstructures of the material. On the contrary, SPS can fabricate materials at rapid heating rate and short sintering time, thus resulting into uniform microstructures $[2,3]$. The SPS technology uses a pulsed DC (direct current) under the application of uniaxial pressure [4], to bring about the consolidation of powders. The process allows the acceleration of material transfer and diffusion phenomena due to plasma generation between the powder particles. This results to breakdown and cleaning of oxide impurities from the material surface. Furthermore, pressure assisted plastic deformation and joule effect aid sinterability and densification [5,6]. Owing to the characteristics of SPS, parameters such as pressure, sintering temperature, holding time and heating rate, plays a role in the densification mechanisms of a consolidated sample [7].

\footnotetext{
* e-mail: sojlags@yahoo.ca
}

The heating mechanism of SPS technique comprises of cooling time and lower sintering temperature, rapid sintering process due to its good heat distribution and great heating rate (up to $1000 \mathrm{~K} / \mathrm{min}$ ) on fabricated samples at microscopic level and macroscopic level $[8,9]$. Researchers have reported that the use of fast heating rates can limit coarsening for some samples that possesses highlevel activation energy for densification than grain growth $[10,11]$. Therefore, by utilizing a higher heating rate where the non densifying mechanisms prevail, densification takes place by volume diffusion and grain boundary, this allow the possibility of having a fine grain retention. However, this could be a challenge for other samples, due to their elevated activation energy for grain growth than that of densification, in this process the heating rate lacks the expected positive effects [12]. Nevertheless, the studies on the effect of heating rate on grain growth and densification of materials prepared by the SPS technique have given rise to several conflicting outcomes [13]. Investigation by Stanciu et al. [11] on the effect of heating rate on the grain size and densification of SPSed $\mathrm{Al}_{2} \mathrm{O}_{3}$ and $\mathrm{MoSi}_{2}$ from $50{ }^{\circ} \mathrm{C} / \mathrm{min}$ to $700^{\circ} \mathrm{C} / \mathrm{min}$ was observed, and the final density of SPSed $\mathrm{Al}_{2} \mathrm{O}_{3}$ was not affected by the heating rate, but it had little effect on the grain size. In the case of the sintered $\mathrm{MoSi}_{2}$, the grain size of the sample was independent of the heating rate value. 
Table 1. The starting materials used for the study.

\begin{tabular}{lcll}
\hline Powder & Particle size & Purity & Supplier \\
\hline Carbon nanotubes & $9.5 \mathrm{~nm}$ & $99.8 \%$ & Nanocyl \\
Nickel & $<3.0 \mu \mathrm{m}$ & $99.5 \%$ & Wear Tech Limited \\
Aluminium & $<25 \mu \mathrm{m}$ & $99.8 \%$ & Technik Gmbh \\
\hline
\end{tabular}

Similarly, the consolidation of alumina powders at different sintering temperatures, heating rate at $50{ }^{\circ} \mathrm{C} / \mathrm{min}$ and $300^{\circ} \mathrm{C} / \mathrm{min}$ respectively was reported by Zhou et al. [14]. The results showed that the sintered samples at $300{ }^{\circ} \mathrm{C} / \mathrm{min}$ had higher densities, with decreased grain sizes as compared to the sintered samples at $50^{\circ} \mathrm{C} / \mathrm{min}$. Contrary to the previous investigations, Shen et al. [15] shows that the density of sintered alumina decreased by $0.6 \%$ with increasing heating rate, especially at $350^{\circ} \mathrm{C} / \mathrm{min}$, and the grain size was smaller due to the higher heating rate. Recently, the role of heating rate was examined on the transparency and microstructure of sintered alumina powder from $2{ }^{\circ} \mathrm{C} / \mathrm{min}$ to $100^{\circ} \mathrm{C} / \mathrm{min}$, at $1150{ }^{\circ} \mathrm{C}$. The results indicated that the porosity, transparency, and grain size increased as the heating rate increased. The grain size of the sintered alumina increased by $89 \%$ from $2{ }^{\circ} \mathrm{C} / \mathrm{min}$ to $100^{\circ} \mathrm{C} / \min [16]$.

The effect of heating rate was studied by Lee et al. [17] during the formation of titanium aluminide through the reactive sintering of $\mathrm{Ti}-48 \% \mathrm{Al}$ powders. It was reported that increasing heating rate favoured the formation of $\mathrm{TiAl}, \mathrm{Ti}_{3} \mathrm{Al}$ and $\mathrm{TiAl}_{3}$ intermetallic compounds. The densification of SPSed TiAl was further assessed by Zofia et al. [18] and they reported that densification of TiAl can be attributed to bulk diffusion of $\mathrm{Al}$, through its contribution in dislocation climb. The process of dislocation glide and twinning are being active in small interparticle regions at the start of the densification cycle. In this present study, carbon nanotubes (CNT) has been used to reinforce the matrix metal (nickel aluminide) because of its promising mechanical properties, and wideranging benefits of the composites in energy and transportation industries. However, the densification mechanisms and grain size analysis of intermetallic material especially CNTs reinforced NiAl has not been sufficiently examined from the literature. This is the reason that motivated the authors to focus on the evaluation of heating rate on the densification and grain size of the composites.

\section{Experimental procedure}

The starting materials utilized are presented in Table 1 . Planetary ball milling machines were used to disperse the carbon nanotubes (CNT) within the admixed matrix powders at the speed of $150 \mathrm{rpm}$. The milling was accomplished in a steel-container consisting different steel balls. Then, the milled powders were charged in a $20 \mathrm{~mm}$ sintering die, enclosed with the sintering punches. The consolidation of the powders took place in the spark plasma sintering machine. The details of the dispersion of nanotubes within the matrix metal and the consolidation process of the samples have been reported [19]. As sintered composite samples were used in this investigation. The data retrieved from the SPS was utilized in evaluating the densification mechanism during the sintering procedure. Tescan Mira 3 XMU (Scanning Electron Microscope; SEM) equipped with Electron Back-scatter Diffraction (EBSD) was utilized to determine the microstructural evolution in the fabricated samples. The Consolidated samples were polished with Eposil M Colloidal Silica for the duration of an hour to achieve a smooth surface, and to depict the features of the microstructures. The grain analysis of the consolidated samples was observed using the EBSD at a tilt angle of $70^{\circ}$ for dynamic focus, step size of $0.5 \mu \mathrm{m}$ and with a voltage of $20 \mathrm{kV}$. The crystallographic orientation was analyzed with AZtecHKL software (Denmark) and the EBSD maps were obtained. The porosity of the consolidated sample was determined with the formula:

$$
\text { Porosity }=(1-\text { relative density }) * 100 \% \text {. }
$$

\section{Results and discussion}

\subsection{Densification behaviour and fractured surface of the samples}

The sintering profile obtained from the SPS was used to assess the densification behaviour of the consolidated samples $(\mathrm{NiAl} / \mathrm{CNT})$ and unreinforced $\mathrm{NiAl}$ at different heating rates from $50^{\circ} \mathrm{C} / \mathrm{min}$ to $150{ }^{\circ} \mathrm{C} / \mathrm{min}$, and at the sintering temperature of $1000^{\circ} \mathrm{C}$. Figure 1 depicts the displacement-time graph of all the consolidated samples respectively. The mechanisms of the densification observed can be described by the following stages [20]: (a) sample activation and refining, (b) sintering neck formation, (c) growth of neck, and (d) plastic deformation. the first and second steps occurred due to plasma discharge between the particles, which leads to the removal of impurities due to voltage breakdown. Therefore, the sample surface heats up, promoting neck formation by evaporation and diffusion. The last two steps materialized because of electric current passage through the necks by joule heating effect. This favored rapid densification and enhanced by the effect of pressure in the fourth stage. Figure 1a indicates the displacement-time graph of the consolidated $\mathrm{NiAl}$ at different heating rates. From the graph, the displacement of the consolidated sample at $50{ }^{\circ} \mathrm{C} / \mathrm{min}$ was observed at $3.62 \mathrm{~mm}$, the sample at $100^{\circ} \mathrm{C} / \mathrm{min}$ showed displacement at $3.22 \mathrm{~mm}$, and the sample at $150^{\circ} \mathrm{C} / \mathrm{min}$ had the highest displacement at $4.15 \mathrm{~mm}$. The displacement decreased as 

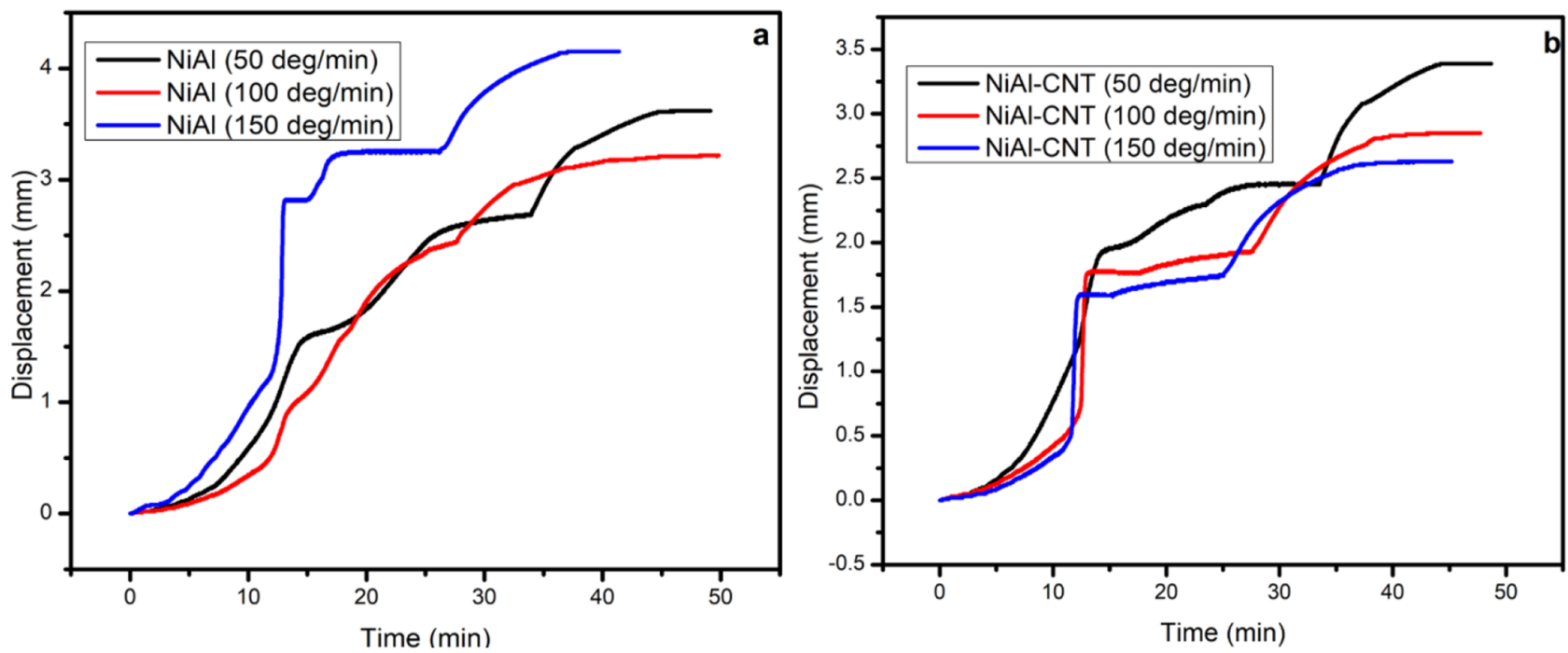

Fig. 1. The plot of the displacement against time at different heating rate (a) NiAl, and (b) NiAl-CNT.
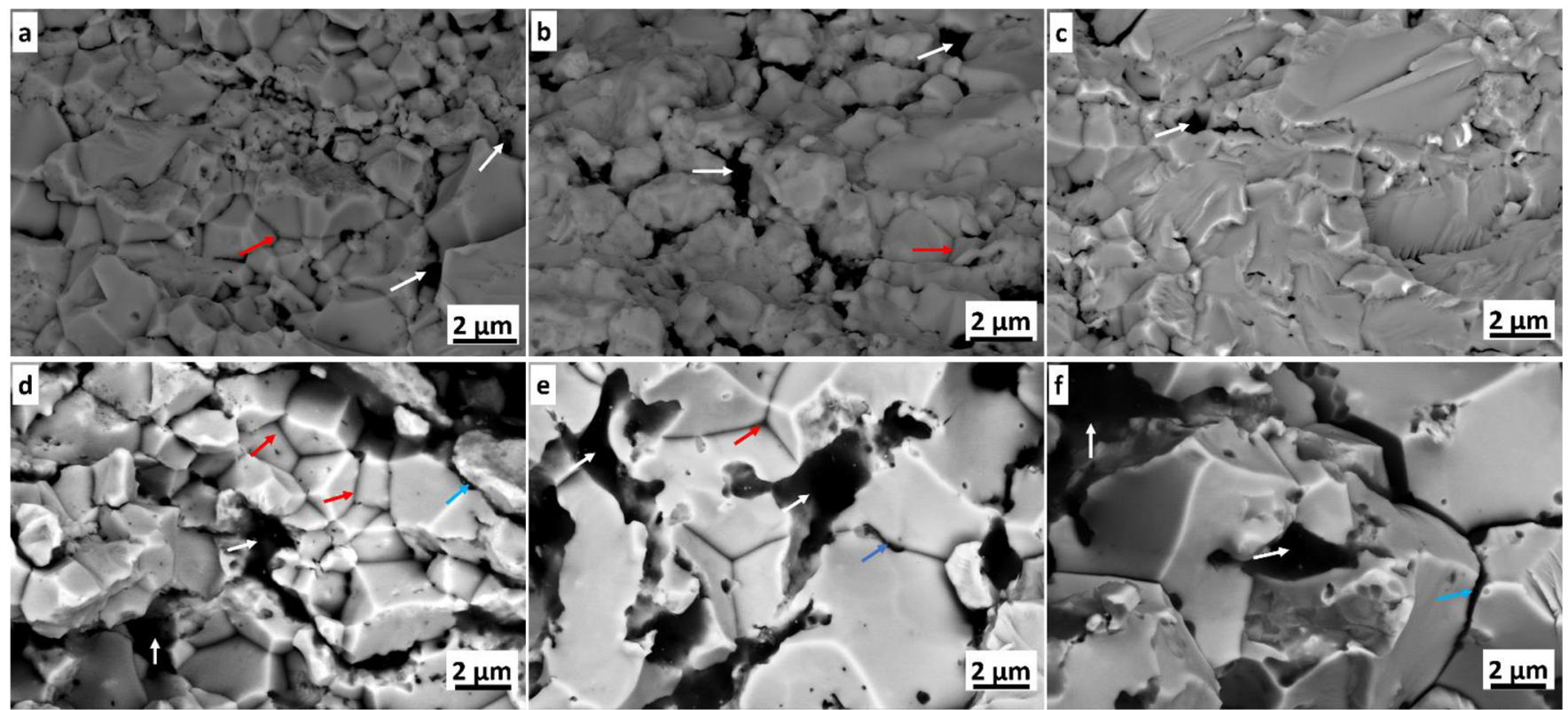

Fig. 2. SEM fractured morphology of the consolidated samples from 50 to $150^{\circ} \mathrm{C} / \mathrm{min}(\mathrm{a}-\mathrm{c}) \mathrm{NiAl}$, and $(\mathrm{d}-\mathrm{f}) \mathrm{NiAl-CNT}$.

the heating rate was increased, but it further increases at the heating rate of $150{ }^{\circ} \mathrm{C} / \mathrm{min}$. This depicts that the rapid heating rate promoted high densification because of the large displacement observed.

Figure $1 \mathrm{~b}$ describes the displacement-time graph of the consolidated composites (NiAl-CNT) at different heating rates. The displacement of the consolidated composite at $50{ }^{\circ} \mathrm{C} / \mathrm{min}$ was observed at $3.39 \mathrm{~mm}$, the composite at $100^{\circ} \mathrm{C} / \mathrm{min}$ showed displacement at $2.85 \mathrm{~mm}$, and the composite at $150{ }^{\circ} \mathrm{C} / \mathrm{min}$ attains displacement at $2.63 \mathrm{~mm}$. The displacement of the consolidated composite decreased with increasing heating rate. It further suggests the detrimental effect of heating rate on the densification of the composites. This is in line with the result reported by Singh et al. [6]. The decrease in displacement at increasing heating rate may be attributed to the lower thermal transfer. The presence of CNT in the composite may induce pores at higher heating rate which retards the sintering mechanisms [9].

The SEM fractured morphology (Fig. 2) was used to buttress the densification mechanisms of the consolidated samples. The fractured surface of the consolidated NiAl (Fig. $2 \mathrm{a}-\mathrm{c}$ ) is characterized with cavities (pointed with white arrows). Figure 2a describes the fracture morphology of the consolidated $\mathrm{NiAl}$ at the heating rate of $50^{\circ} \mathrm{C} / \mathrm{min}$, indicating necking of particles as represented with red arrow. 


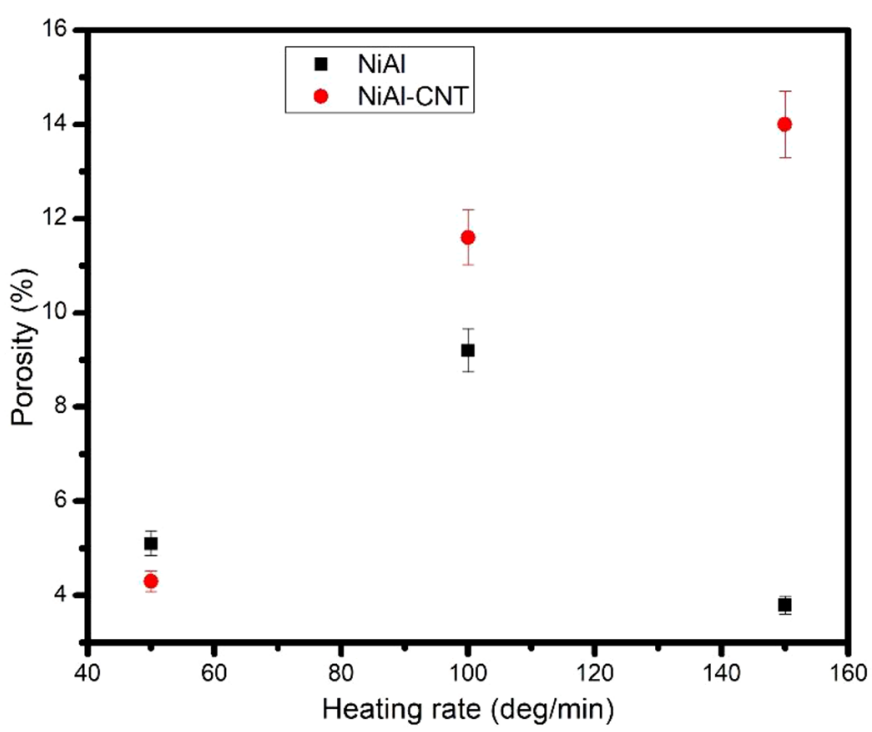

Fig. 3. The illustration of the porosity with heating rate (a) NiAl, and (b) NiAl-CNT.

Similar behaviour was observed for the consolidated NiAl at $100^{\circ} \mathrm{C} / \mathrm{min}$ (Fig. $2 \mathrm{~b}$ ), with the presence of pronounced cavities. This suggests that the particles are not well bonded which is an indication of the low displacement seen in Figure 1. The consolidated sample at $150^{\circ} \mathrm{C} / \mathrm{min}$ (Fig. 2c), had a fractured surface with reduced cavities and the particles are well metallurgically bonded. This occurrence maybe attributed to rapid neck formation of the particles and it maybe responsible for the high displacement observed in Figure 1. The fractured morphology of all the consolidated NiAl at different heating rate displayed a rock candy features which indicates intergranular fracture.

The fracture morphology of the consolidated NiAlCNT composites (Fig. 2d-f) displayed the presence of neck formation (pointed with white arrows), cavities (pointed with red arrows) and cracks (pointed with blue arrows) at different heating rate. The consolidated composites at the heating rate of $50{ }^{\circ} \mathrm{C} / \mathrm{min}$ (Fig. 2d) showed presence of cavities, with a few neck formations [21]. These cavities became bigger as observed in the composite (Fig. 2e). At this stage $\left(100^{\circ} \mathrm{C} / \mathrm{min}\right)$, there were fewer necks formed as compared to Figure 2d. In Figure 2f, more distinct cavities and cracks were seen. This explained why the displacement decreases with the heating rate. The cavities noticed from the sintered composites maybe due to the agglomerated CNTs. The fractured morphology of all the consolidated composites at different heating rate may have displayed transgranular fracture.

\subsection{Porosity of the samples}

Figure 3 shows the porosity of the consolidated samples at $1000{ }^{\circ} \mathrm{C}$ at different heating rates. The porosity of the consolidated $\mathrm{NiAl}$ at $50{ }^{\circ} \mathrm{C} / \mathrm{min}$ was observed to be $5.1 \%$. When the heating rate was increased to $100^{\circ} \mathrm{C} / \mathrm{min}$, the porosity had increased to $9.2 \%$. This indicates that the pores in the consolidated samples increases with heating rate. However, the porosity of the consolidated sample at $150{ }^{\circ} \mathrm{C} / \mathrm{min}$ was found to be $3.8 \%$ which depicts high relative density and less pores. Furthermore, the porosity of the consolidated composite increased with increasing heating rate from $50^{\circ} \mathrm{C} / \mathrm{min}$ to $150^{\circ} \mathrm{C} / \mathrm{min}$. The porosities of the composites were observed to be $4.3 \%, 11.6 \%$, and $14 \%$ respectively. This could be accredited to decrease in neck formation and lack of particle arrangements at high heating rate which hinders good metallurgical bonding. Also, the presence of CNT agglomerates could create pores which hinders diffusion during the SPS process [22].

\subsection{Analysis of the grain size}

Figure 4 illustrates the grain size analysis of the consolidated samples at varied heating rates from 50 to $150{ }^{\circ} \mathrm{C} / \mathrm{min}$. The maps of the consolidated samples were obtained from the electron backscattered patterns (EBSP) after indexing. The maps revealed the grain boundaries of the samples with some black regions. These are the regions where flamenco had difficulties in indexing the EBSPs due to the occurrence of unknown phases or grain boundaries deformed areas, known as low-EBSP areas. The reason for this could be due to the presence of porosity where the CNTs are agglomerated [23]. Figure $4 \mathrm{a}-\mathrm{c}$ depicts the grain boundaries of the consolidated NiAl. It was observed that the grain arrangement was similar (the differences are not obvious) as the heating rate increases from 50 to $150{ }^{\circ} \mathrm{C} / \mathrm{min}$, although the samples had some porosities. However, the grain boundaries of the consolidated composites increased as the heating rate increases, as represented in Figure $4 \mathrm{~d}-\mathrm{f}$. The composite at $50^{\circ} \mathrm{C} / \mathrm{min}$ had similar grain boundaries with the consolidated $\mathrm{NiAl}$, maybe because it had enough power input for particle bonding. The presence of the agglomeration of CNTs could have created some pores in the composites which hinders diffusion. It depicts that at high heating rate, more porosities were observed in the composite which could have been responsible for improper particle bonding, resulting into large grains in the composites at $150{ }^{\circ} \mathrm{C} / \mathrm{min}$. Studies have shown that rapid heating rate impedes surface diffusion for coarsening processes, thereby leading to the decrease in grain size $[15,24]$. However, this study agrees with Murayama et al. [25], which reported that high heating rate results in grain size increase because of high defect concentration formed during densification and rapid particle deformation. Furthermore, fast heating rate produces large direct current which may cause defect formation because of high temperature plasma formed on the surface of the particles, which induced dynamic grain growth [26]. Similarly, the microstructures of the consolidated NiAl and NiAl-CNT depict the presence of pores as observed from Figure 2. This is because consolidated samples go through non-thermal and thermal effects, rearrangement of sample particle, and deformation (both localized and bulk) during SPS mechanisms which affects the densification, grain growth and mechanical properties of the samples [27]. However, rapid heating rate results into the formation of large thermal gradients which may lead to the sinterability of the outer region of the sample before the inner region of the sample, leading to residual porosity [28]. 

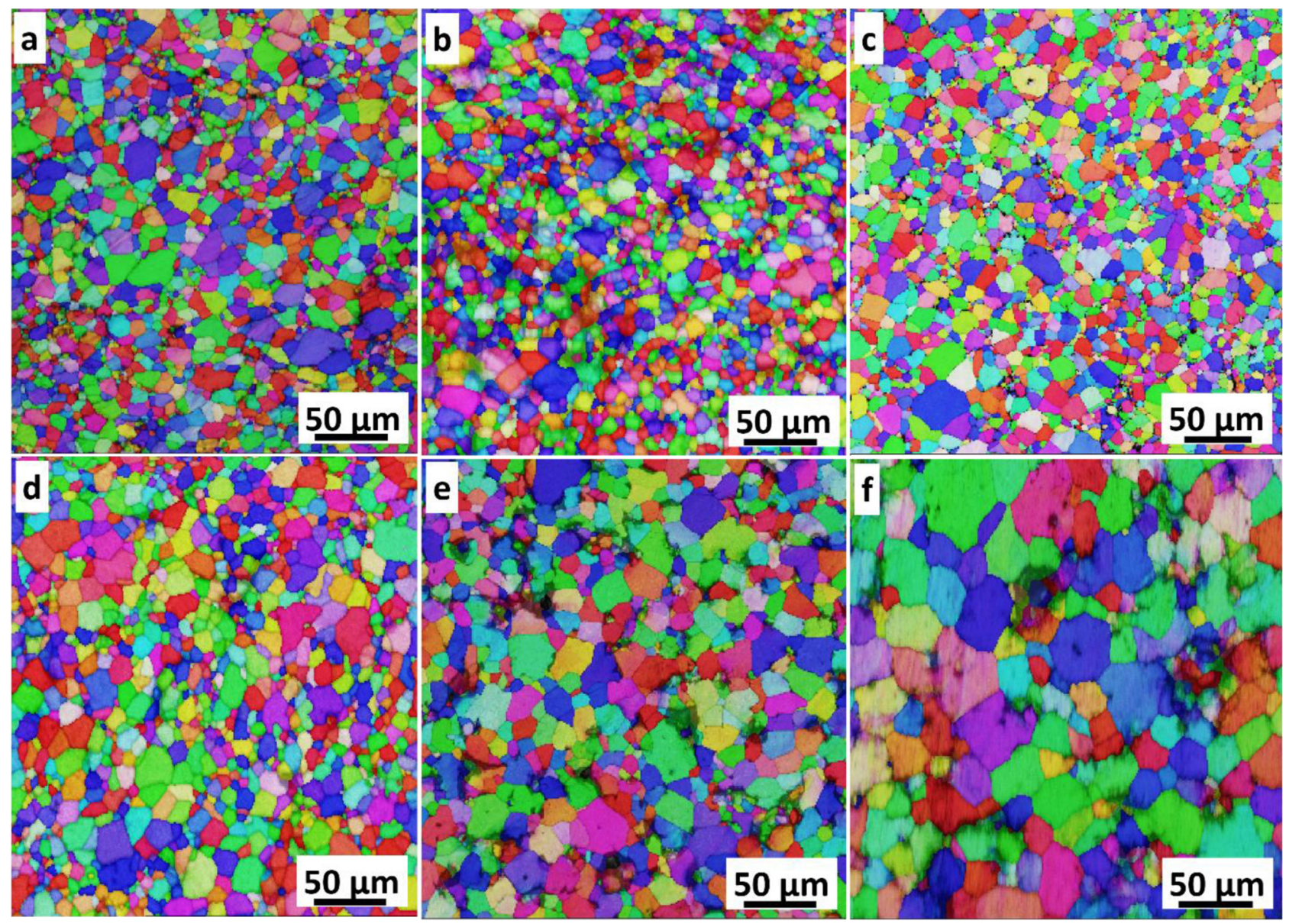

Fig. 4. Illustration of the grain boundaries of the sintered samples $(\mathrm{a}-\mathrm{c}) \mathrm{NiAl}$, and $(\mathrm{d}-\mathrm{f}) \mathrm{NiAl}-\mathrm{CNT}$.
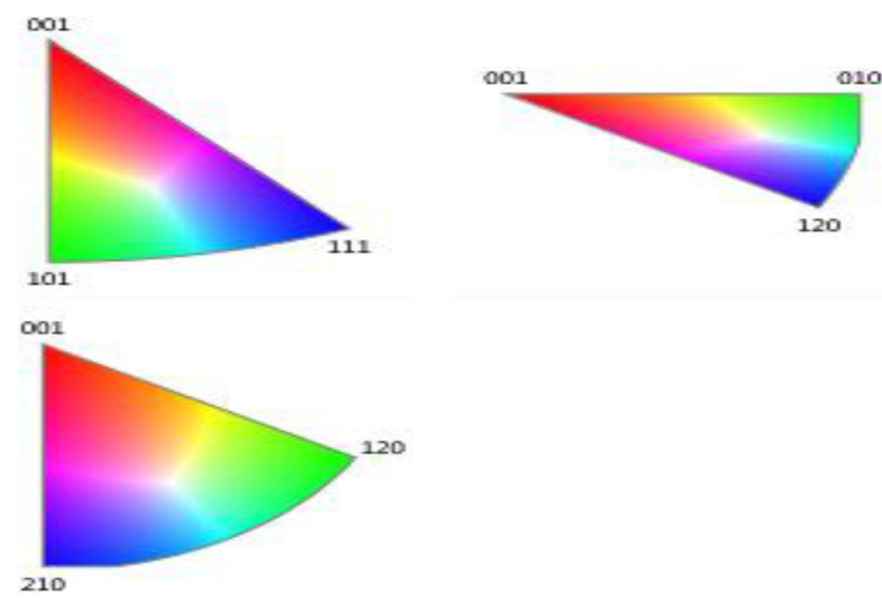

Fig. 5. Inverse pole maps of the consolidated samples.

Figure 5 describes the inverse pole figure (IPF) of the consolidated samples at different heating rates. IPF is used to show the alignment of the crystal directions with the consolidated samples' axes at different heating rates. It can also be utilized to predict the texture of a sample. Figure 5 shows the IPF maps of the consolidated samples, which indicated that there is no predominance of any colour. This suggests that the consolidated samples do not have texture or show the intensity of any colour [29].

The mean grain size of the consolidated samples was evaluated using the line intercept method, according to ASTM E112 (Fig. 6). The mean grain size $(\mu \mathrm{m})$ of the consolidated NiAl from $50{ }^{\circ} \mathrm{C} / \mathrm{min}$ to $150{ }^{\circ} \mathrm{C} / \mathrm{min}$ was measured as $3.24 \pm 2.5 \mu \mathrm{m}, \quad 3.14 \pm 2.1 \mu \mathrm{m}$, and $3.27 \pm$ $2.4 \mu \mathrm{m}$ respectively. It could be seen that there is little disparity in the grain size of the NiAl samples. However, the mean grain size of the consolidated composite (ball milled after $60 \mathrm{~min}$ ) from $50-150^{\circ} \mathrm{C} / \mathrm{min}$ was measured as $3.93 \pm 2.5 \mu \mathrm{m}, 4.78 \pm 3.4 \mu \mathrm{m}$, and $8.05 \pm 5.8 \mu \mathrm{m}$ respectively. Furthermore, the distribution of the grain size of the consolidated samples is presented in Figure 7. The length of the grain was used to compute the grain size of the consolidated samples, Figure $7 \mathrm{a}-\mathrm{c}$ shows the distribution of the consolidated NiAl. The highest count of the grain size was observed at $17 \mu \mathrm{m}, 11 \mu \mathrm{m}$, and $14 \mu \mathrm{m}$ from $50^{\circ} \mathrm{C} / \mathrm{min}$ to $150^{\circ} \mathrm{C} / \mathrm{min}$. In the case of the consolidated NiAl-CNT (Fig. $7 \mathrm{~d}-\mathrm{f}$ ), the highest count of the grain size was observed at $10.5 \mu \mathrm{m}, 16.5 \mu \mathrm{m}$, and $29.5 \mu \mathrm{m}$ respectively from $50^{\circ} \mathrm{C} / \mathrm{min}$ to $150^{\circ} \mathrm{C} / \mathrm{min}$. Large grain size was observed at $150^{\circ} \mathrm{C} / \mathrm{min}$ from Figure $7 \mathrm{f}$. 


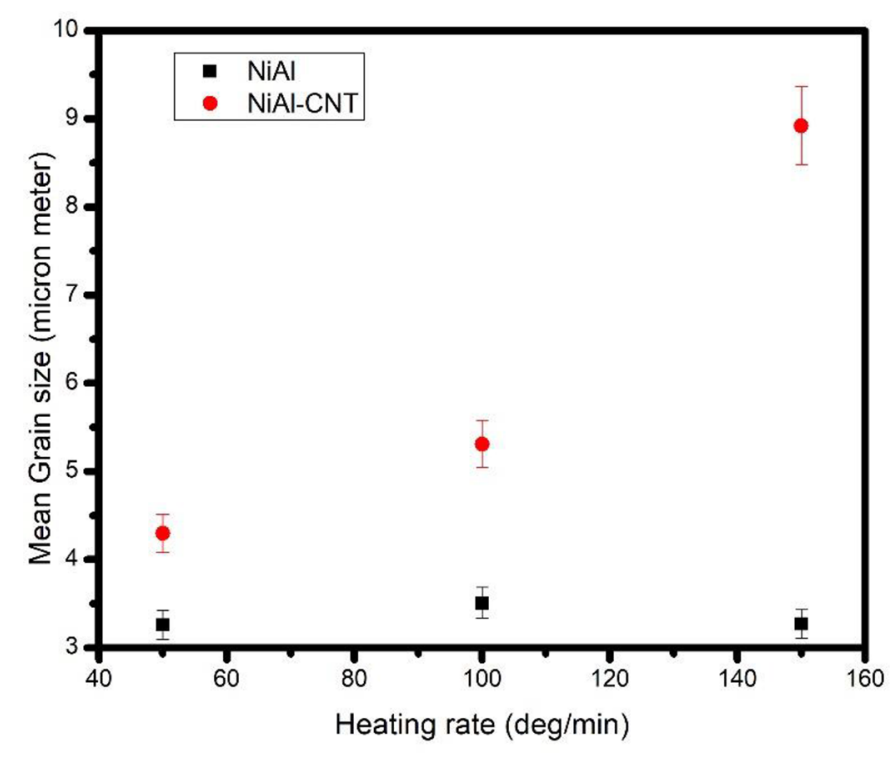

Fig. 6. The mean grain size plots of the consolidated specimens.
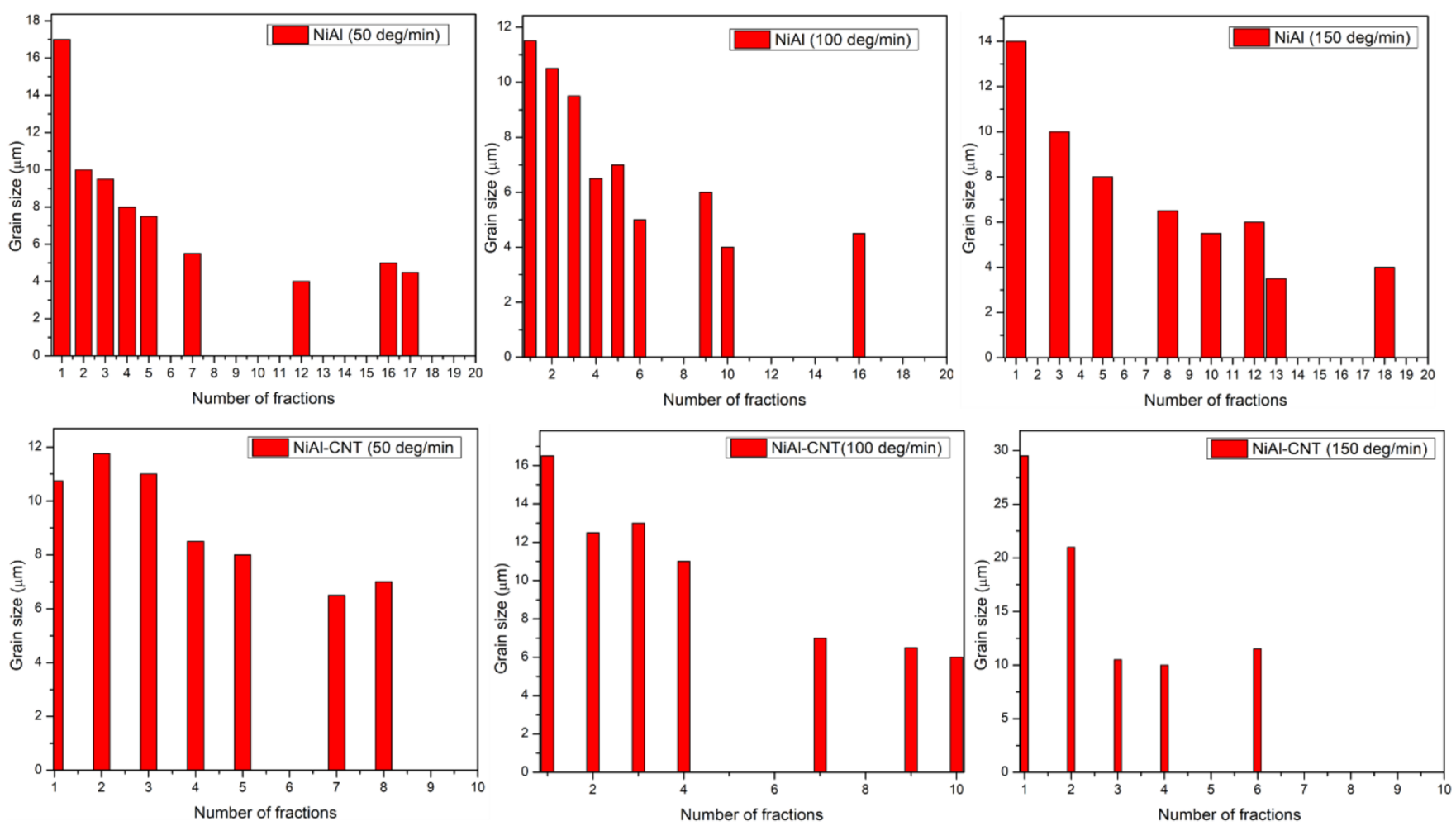

Fig. 7. The grain size distribution of the consolidated specimens at different heating rate.

\section{Conclusions}

This research work evaluated the role of sintering parameter on the densification mechanism and grain analysis of the fabricated composites. The displacement of the consolidated samples are dependent on the heating rate. The punch displacement of the sintered $\mathrm{NiAl}$ decreases with the heating rate until it further increases at the heating rate of $150^{\circ} \mathrm{C} / \mathrm{min}$. The trend observed for the sintered composites are different because the punch displacement decreases with increasing heating rate. The use of EBSD technique was also helpful in revealing the arrangement of the grains of the sintered samples. It depicted the influence of heating rate on the grain analysis because of the presence of high defect concentration formed during densification and rapid particle deformation. This phenomenon caused the increase in the grain sizes of the sintered composites as the heating rate was increased. The variation of grains of the sintered $\mathrm{NiAl}$ was non conspicuous. 
Acknowledgements. The authors would like to thank the University of Johannesburg, South Africa for their funding and Dr. Lukas Bichler's Lab (UBCO, Canada) for the use of their facilities.

\section{References}

1. Z.A. Munir, U. Anselmi-Tamburini, M. Ohyanagi, The effect of electric field and pressure on the synthesis and consolidation of materials: A review of the spark plasma sintering method, J. Mater. Sci. 41 (2006) 763-777

2. S.Q. Guo, T. Nishimura, Y. Kagawa, J.M. Yang, Spark plasma sintering of zirconium diborides, J. Am. Ceram. Soc. 91 (2008) 2848-2855

3. T. Nishimura, M. Mitomo, H. Hirotsuru, M. Kawahara, Fabrication of silicon nitride nano-ceramics by spark plasma sintering, J. Mater. Sci. Lett. 14 (1995) 1046-1047

4. B.J. Babalola, M.B. Shongwe, A.L. Rominiyi, P.L. Lepele, A.P.I. Popoola, The fabrication and characterization of spark plasma sintered nickel based binary alloy at different heating rate, J. Micro Nano-Manufactur. 7 (2019) 31004-31005

5. A.L. Rominiyi, M.B. Shongwe, N. Maledi, B.J. Babalola, P.A. Olubambi, Synthesis, microstructural and phase evolution in $\mathrm{Ti}-2 \mathrm{Ni}$ and $\mathrm{Ti}-10 \mathrm{Ni}$ binary alloys consolidated by spark plasma sintering technique, Int. J. Adv. Manuf. Technol. 104 (2019) 1041-1049

6. L.K. Singh, A. Bhadauria, S. Jana, T. Laha, Effect of sintering temperature and heating rate on crystallite size, densification behaviour and mechanical properties of Al-MWCNT nanocomposite consolidated via spark plasma sintering, Acta Metall. Sin. English Lett. 31 (2018) 1019-1030

7. Y. Cheng, Z. Cui, L. Cheng, D. Gong, W. Wang, Effect of particle size on densification of pure magnesium during spark plasma sintering, Adv. Powder Technol. 28 (2017) $1129-1135$

8. A.I. Journal, O.E. Falodun, B.A. Obadele, S.R. Oke, O. Oladeji, P.A. Olubambi, O.E. Falodun, B.A. Obadele, S.R. Oke, Effect of TiN and TiCN additions on spark plasma sintered Ti - 6Al - 4V, Part. Sci. Technol. 38 (2020) 156-165

9. A.M. Okoro, R. Machaka, S.S. Lephuthing, S.R. Oke, M.A. Awotunde, P.A. Olubambi, Evaluation of the sinterability, densification behaviour and microhardness of spark plasma sintered multiwall carbon nanotubes reinforced Ti6Al4V nanocomposites, Ceram. Int. (2019)

10. W. Zeng, L. Gao, L. Gui, J. Guo, Sintering kinetics of $\alpha-\mathrm{Al}_{2} \mathrm{O}_{3}$ powder, Ceram. Int. 25 (1999) 723-726

11. L.A. Stanciu, V.Y. Kodash, J.R. Groza, Effects of heating rate on densification and grain growth during field-assisted sintering of $\alpha-\mathrm{Al}_{2} \mathrm{O}_{3}$ and $\mathrm{MoSi}_{2}$ powders, Metall. Mater. Trans. A Phys. Metall. Mater. Sci. 32 (2001) 2633-2638

12. S. Gephart, J. Singh, A. Kulkarni, Field assisted sintering of $\mathrm{SiC}$ using extreme heating rates, J. Mater. Sci. 46 (2011) $3659-3663$
13. K. Hu, X. Li, S. Qu, Y. Li, Effect of heating rate on densification and grain growth during spark plasma sintering of $93 \mathrm{~W}-5$. 6Ni-1.4Fe heavy alloys, Metall. Mater. Trans. A Phys. Metall. Mater. Sci. 44 (2013) 4323-4336

14. Y. Zhou, K. Hirao, Y. Yamauchi, S. Kanzaki, Effects of heating rate and particle size on pulse electric current sintering of alumina, Scr. Mater. 48 (2003) 1631-1636

15. Z. Shen, M. Johnsson, Z. Zhao, M. Nygren, Spark plasma sintering of alumina, J. Am. Ceram. Soc. 85 (2002) 1921-1927

16. B.N. Kim, K. Hiraga, K. Morita, H. Yoshida, Effects of heating rate on microstructure and transparency of sparkplasma-sintered alumina, J. Eur. Ceram. Soc. 29 (2009) $323-327$

17. T.W. Lee, C.H.Ã. Lee, The effect of heating rate on the reactive sintering of $\mathrm{Ti} \pm 48 \% \mathrm{Al}$ elemental powder mixture, 7 (1998) 1367-1370

18. Z. Trzaska, G. Bonnefont, G. Fantozzi, J.P. Monchoux, Comparison of densification kinetics of a TiAl powder by spark plasma sintering and hot pressing, Acta Mater. 135 (2017) 1-13

19. O.O. Ayodele, A.O. Adegbenjo, M.A. Awotunde, M.B. Shongwe, P.A. Olubambi, The influence of heating rate on the microstructural evolutions and mechanical properties of spark plasma sintered multi-walled carbon nanotubes reinforced NiAl intermetallic matrix composites, Mater. Sci. Eng. A. 773 (2020) 138869

20. Z. Zhaohui, W. Fuchi, W. Lin, L. Shukui, S. Osamu, Sintering mechanism of large-scale ultrafine-grained copper prepared by SPS method, Mater. Lett. 62 (2008) 3987-3990

21. S. Diouf, A. Molinari, Densification mechanisms in spark plasma sintering: Effect of particle size and pressure, Powder Technol. 221 (2012) 220-227

22. L. Shahrdami, A. Sedghi, M.H. Shaeri, Microstructure and mechanical properties of $\mathrm{Al}$ matrix nanocomposites reinforced by different amounts of CNT and SiCW, Compos. Part B Eng. (2019) 107081

23. S. Suárez, E. Ramos-Moore, B. Lechthaler, F. Mücklich, Grain growth analysis of multiwalled carbon nanotubereinforced bulk Ni composites, Carbon N. Y. 70 (2014) $173-178$

24. I.K. Aliyu, N. Saheb, S.F. Hassan, N. Al-Aqeeli, Microstructure and Properties of Spark Plasma Sintered Aluminum Containing 1 wt.\% SiC Nanoparticles, Metals (Basel). 5 (2015) 70-83

25. N. MURAYAMA, W. SHIN, Effect of rapid heating on densification and grain growth in hot pressed alumina, J. Ceram. Soc. Japan. 108 (2000) 799-802

26. J. Besson, M. Abouaf, Grain growth enhancement in alumina during hot isostatic pressing, Acta Metall. Mater. 39 (1991) 2225-2234

27. P. Cavaliere, B. Sadeghi, A. Shabani, Carbon nanotube reinforced aluminum matrix composites produced by spark plasma sintering, J. Mater. Sci. 52 (2017) 8618-8629 
28. H. Zhang, Y. Xu, B. Wang, X. Zhang, J. Yang, K. Niihara, Effects of heating rate on the microstructure and mechanical properties of rapid vacuum sintered translucent alumina, Ceram. Int. 41 (2015) 12499-12503
29. S. Simões, F. Viana, M.A.L. Reis, M.F. Vieira, Improved dispersion of carbon nanotubes in aluminum nanocomposites, Compos. Struct. 108 (2014) 992-1000

Cite this article as: Olusoji Oluremi Ayodele, Mary Ajimegoh Awotunde, Bukola Joseph Babalola, Peter Apata Olubambi, Spark plasma sintering of CNT-NiAl nanocomposites- Process parameter, densification mechanism, and grain analysis, Manufacturing Rev. 8, 25 (2021) 